\title{
SCIENTIFIC REPORTS

\section{OPEN Poly (3, 4-ethylene dioxythiophene) Supported Palladium Catalyst prepared by Galvanic Replacement Reaction for Methanol Tolerant Oxygen Reduction}

\begin{abstract}
Pandia Rajathi $\mathbf{M}^{1,2} \&$ Sheela Berchmans ${ }^{2 *}$
Herein, we propose a facile electrochemical approach for the synthesis of Pd loaded poly 3, 4-ethylenedioxythiophene (PEDOT) electrodeposited on glassy carbon electrode (GCE) resulting in high surface area. The catalyst preparation is initiated with EDOT polymerization on GCE surface by electrochemical potential cycling method, followed by the electrodeposition of Cu from a $2 \mathrm{mM}$ solution of $\mathrm{CuSO}_{4}$ in $0.1 \mathrm{M} \mathrm{NaClO}_{4}$ at a constant potential of $+0.34 \mathrm{~V} v$ s. SHE in the form of Cu nanocubes on the PEDOT surface. Pd-PEDOT catalyst was then prepared by the partial substitution of copper by galvanic displacement with various concentrations of $\mathrm{PdCl}_{2}$. The prepared $\mathrm{Pd} / \mathrm{PEDOT}$ electrocatalyst is found to be methanol resistant indicating its usefulness as fuel cell cathode. The prepared catalyst supports two electron transfer of oxygen reduction reaction in $0.5 \mathrm{M} \mathrm{H}_{2} \mathrm{SO}_{4}$. The effects of Pd and Cu contents and the quantity of PEDOT, mass and specific activities were studied. At a relatively low Pd loading of $0.57 \mathrm{ng} / \mathrm{cm}^{2}$, the Pd/PEDOT should be a cost-effective alternative cathode catalyst for direct methanol fuel cells, DMFCs. This work explains the usefulness of PEDOT as good catalyst supporting material which is prepared by an eco-friendly electrochemical route.
\end{abstract}

The global demand for electricity generation and its vast usage has motivated the researchers to find alternative renewable energy solutions. Electrochemical conversion of chemical energy into electrical energy is more advantageous than heat engine based energy conversion where Carnot's theorem poses limitation. The electrochemical energy conversion devices that are of high significance are fuel cells, electrolysers, batteries, supercapacitors and redox flow batteries. There is a dire need for electrochemical energy conversion devices as the demand for off grid portable devices and electric vehicles increases. In a fuel cell the conversion of chemical to electrical energy happens by anodic oxidation of fuel resulting in the liberation of electrons which flows through the exterior circuit and arrive at the cathode wherein most of the cases oxygen reduction occurs. Small molecules like hydrogen, methanol, ethanol, formic acid etc., act as fuels in fuel cells ${ }^{1}$. Fuel cell driven electrochemical engines would offer clean source of energy and such engines would be noise free, vibration free and devoid of harmful gaseous emissions. Pt is the best catalyst ever known for fuel cell applications. The poor kinetics of oxidation of fuels at the anode and low abundance combined with the exorbitant cost of Pt make the cost of the device very high. Hence researchers are focusing on alternate catalysts with enhanced performance Also, investigations on the electrochemical oxidation of small molecules like methanol, formic acid are on the increase besides hydrogen ${ }^{2-7}$. For many of the applications including fuel cells in which Pt reigns supremacy, the current trend is to make use of alloy of noble metals with non-noble metals ${ }^{8,9}$. Such alloy catalysts are helpful in reducing the overall cost of the catalyst and exhibit much better performance and high selectivity ${ }^{10-14}$. Nowadays, metallic platinum $(\mathrm{Pt})$ and Pt-based alloys are considered widely popular and superior electrocatalysts for cathodic reaction (oxygen reduction, ORR) in fuel cell applications, metal air batteries, chloralkali electrolysis, water electrolysis, metal corrosion processes etc., In addition to their low abundance and exorbitant cost of Pt based catalysts, they also suffer from low stability, and their susceptibility to fuel (e.g., methanol) poisoning effects. Therefore, we are faced with the big 
challenge of development of Pt-free electrocatalysts for ORR with improved catalytic performance and durability. Owing to the similarity of Palladium to $\mathrm{Pt}$ in terms of crystal structure, electronic configuration and its position at the apex of the volcano plot for ORR activity of pure metals as published by Norskov et al., Pd has emerged as a suitable alternative cathode catalyst for fuel cell applications ${ }^{15}$. The high availability and low cost of Pd are the additional advantageous features in support of Pd being a suitable cathode catalyst. It has been shown that Pd-based electro catalysts exhibit good ORR activity in alkaline media. Also it is known that Pd-based electrocatalysts exhibit poor catalytic activity towards ORR in acidic media when compared to Pt-based electrocatalysts. In order to prevent leaching of metal/alloy nanoparticle catalysts from the electrode surface supporting matrices need to be incorporated on the electrode surface. Supporting matrices provide additional advantages such as (1) improved surface area caused by better distribution of nanoparticles (2) enhanced diffusion of electroactive species through porous supports (3) promoting catalytic activity by increasing electron transfer rates/decreasing Fermi level of catalysts. Usually carbonaceous materials, metal oxides and polymers are used as support materials for catalysts. Although carbonaceous materials are traditionally used as supporting materials, the problems associated due to carbon corrosion necessitate the quest for alternate supports for catalysts. Conducting polymers belong to the class of smart materials with promising and novel applications such as thin film field effect transistors, polymeric light emitting diodes, magnetic shielding materials, sensor technology and so on ${ }^{16-19}$. Conducting polymers are ideal for a broad range of applications because of their special properties, such as high conductivity, stability in air and ease of preparation. Also they can act as a supporting matrix for a dispersed catalyst providing a large surface area that is essential for effective electrocatalysis. In this investigation, the conducting polymer aids high catalytic activity of the nano sized catalytic material. Generally, the combination of chemically prepared polymer and Pd nanoparticles leads to a material with unique properties suitable for multifarious applications and they are predicted as excellent catalysts for oxygen reduction in alkaline medium ${ }^{20}$. In order to avoid aggregation, poor distribution and leaching of naked Pd NPs, conducting polymers provide an ideal choice for catalyst supports. A new strategy of galvanic displacement is adopted in this work to obtain nano sized and well dispersed Pd NPs supported on PEDOT matrix without stabilizers. The literature reports on Pd based ORR catalysts reveal that only carbonaceous materials, metal oxides, chalcogenides and metal carbides have been evaluated so far as catalyst supports ${ }^{21}$. Further only few catalyst preparations involve electrochemical methods. Hence, this paper discusses the first attempt made towards the evaluation of PEDOT as suitable catalyst supports for Pd where the nanostructured $\mathrm{Pd}$ catalyst has been prepared by electrodeposition of $\mathrm{Cu}$ followed by galvanic replacement of $\mathrm{Pd}$. It is well known that Pd can galvanically displace $\mathrm{Cu}^{22,23}$. Motivated by the preceding studies, we planned a strategy of initially depositing Cu on PEDOT matrix and then impregnating Pd NPs by galvanic displacement phenomenon between $\mathrm{Pd}$ ions and $\mathrm{Cu}$. Pd has higher formal electrode potential then $\mathrm{Cu}$ and therefore $\mathrm{Pd}$ replaces the $\mathrm{Cu}$ from $\mathrm{Cu}$ nanocubes on PEDOT surface and thus formed Pd NPs which resembled shrimp like structure. Moreover, the electrochemical data indicate that the Pd/PEDOT catalyst simultaneously exhibits better activity for oxygen reduction reaction in acid medium along with methanol tolerance and can be used as cathode in methanol fuel cell and for hydrogen peroxide preparation.

\section{Experimental Methods}

Reagents. Analytical grade chemicals were used without further purification for all the experiments. The monomer 3,4-ethylenedioxythiophene (EDOT, TCI), tetrabutyl ammonium perchlorate $\left(\mathrm{TBAClO}_{4}\right.$, Fluka), acetonitrile (E-Merck), copper sulphate (Hi Media), sodium perchlorate (Sigma-Aldrich), sulphuric acid (E-Merck), palladium (II) chloride (sigma-Aldrich) and acetonitrile (ACN) were pure and used as received.

Preparation of PEDOT on Glassy carbon, GC surface. The GC electrode was subjected to pre-treatment by polishing on alumina slurry using emery cloth followed by sonication in acetone + water mixture and water respectively. After the pre-treatment, the cleaned GC electrode was dried under vacuum. Then the dried GC electrode was investigated by cyclic voltammetry in the scan range from $0.0 \mathrm{~V}$ to $1.4 \mathrm{~V} v s$. SHE. Then the electrode was washed with milli-Q water and allowed to dry. The $20 \mathrm{mM}$ of EDOT monomer was prepared in $50 \mathrm{ml}$ of acetonitrile and $50 \mathrm{mM}$ of tetrabutyl ammonium perchlorate and was used for electropolymerization. The EDOT was electrochemically polymerised on GC electrode by cyclic voltammetry between the potential limits $-0.65 \mathrm{~V}$ and $1.25 \mathrm{~V} v s . \mathrm{Ag}^{+}$at a scan rate of $0.05 \mathrm{~V} / \mathrm{s}$. A smooth thin blue coloured film was formed in 10 cycles when an $\mathrm{Ag}^{+}$and platinum foil acted as the pseudo reference and counter electrodes for the electrochemical cycling experiments. The PEDOT/GC electrode was then rinsed with ACN solution, to remove the excess of PEDOT ${ }^{24}$.

Electrochemical deposition of Cu NPs on PEDOT/GC. The PEDOT/GC electrode was investigated

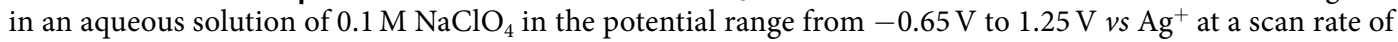
$0.05 \mathrm{~V} / \mathrm{s}$. Cu was electrochemically deposited on PEDOT/GC electrode using a $2 \mathrm{mM}$ solution of $\mathrm{CuSO}_{4}$ in $0.1 \mathrm{M}$ $\mathrm{NaClO}_{4}$ at a constant potential of $+0.34 \mathrm{~V}$ vs. SHE for $120 \mathrm{~s}$. Then the electrodeposited $\mathrm{Cu}$ on PEDOT electrode was washed with milli- $\mathrm{Q}$ water. The $\mathrm{Cu}$ modified PEDOT/GC electrode was examined by cyclic voltammetry in the scan range from $0.0 \mathrm{~V}$ to $1.25 \mathrm{~V}$ at a scan rate of $0.05 \mathrm{~V} / s v s$. SHE.

Galvanic replacement of copper by Palladium. The Cu/PEDOT electrode was subjected to the galvanic replacement reaction and the $\mathrm{Cu}$ NPs were replaced by Pd NPs. The $\mathrm{Cu} / \mathrm{PEDOT}$ electrode was kept immersed in different concentrations $(0.1,0.5,1,2$, and $3 \mathrm{mM})$ of Palladium chloride $\left(\mathrm{PdCl}_{2}\right)$ solutions for 30 minutes without any disturbance. After 30 minutes, the electrode was washed with Milli-Q water and was then allowed to dry for few minutes.

Electrochemical characterisation. The electropolymerization was carried out as described by us earlier ${ }^{24}$ and as mentioned in section 2.2. Briefly electropolymerisation was carried out on a well-polished and cleaned GC electrode from a $0.02 \mathrm{M} \mathrm{EDOT} \mathrm{(3,4-ethylenedioxythiophene} \mathrm{monomer)} \mathrm{dissolved} \mathrm{in} 100 \mathrm{ml}$ of a $0.05 \mathrm{M}$ solution 


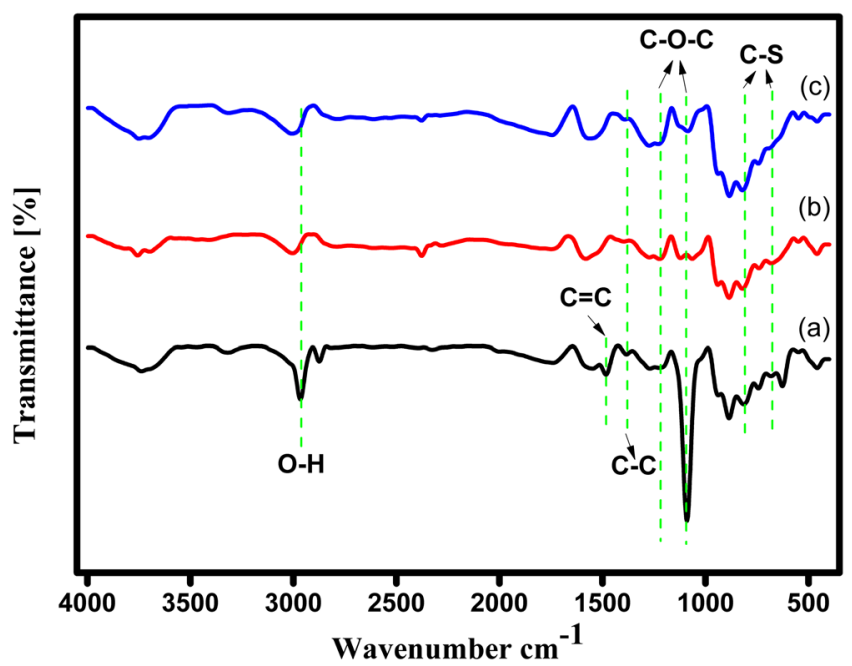

Figure 1. FT-IR Spectra for (a) polymerized EDOT monomer (PEDOT), (b) electro deposited Cu-PEDOT, and (c) galvanically replaced Pd on Cu-PEDOT.

of $\mathrm{TBAClO}_{4}$ (tetrabutyl ammonium perchlorate) in acetonitrile. Potential cycling (20 segments) was conducted between the potentials $-0.65 \mathrm{~V}$ and $+1.25 \mathrm{~V} v s$. an $\mathrm{Ag}^{+} / \mathrm{Ag}$ reference electrode. A Pt foil was used as the counter electrode. Subsequent to polymerization, the GC electrode was rinsed completely with acetonitrile. Cu was electrodeposited on GC/PEDOT in the form of nanoparticles (NPs) at a constant potential of $+0.34 \mathrm{~V} v \mathrm{~s}$. SHE $(120 \mathrm{~s}$ of deposition) from a $0.002 \mathrm{M}$ solution of $\mathrm{CuSO}_{4}$ in $0.1 \mathrm{M} \mathrm{NaClO}_{4}$ solution. The Milli-Q water $(\rho=18.2 \mathrm{M} \Omega \mathrm{cm})$ was used to prepare the electrolyte solution. The mass of electrodeposited $\mathrm{Cu}$ was calculated by cyclic voltammetry (CV). The Cu NPs were partially replaced by Pd by galvanic displacement reaction (GDR) by immersing the $\mathrm{Cu} \mathrm{NP}$ modified PEDOT/GC electrode for $30 \mathrm{~min}$ in $\mathrm{PdCl}_{2}$ solutions of different concentrations. The galvanic replacement phenomenon was confirmed by $\mathrm{CV}$ in $0.5 \mathrm{M}$ of $\mathrm{H}_{2} \mathrm{SO}_{4}$. The charge, mass and electroactive surface area (EASA) of Pd-Cu PEDOT/GC were calculated from CV data. The same procedure was repeated for different concentrations of $\mathrm{PdCl}_{2}$. Thus fabricated Pd/PEDOT/GC electrocatalyst was used to study the methanol tolerant oxygen reduction reaction. The potential values are stated with reference to $\mathrm{SHE} \mathrm{or}_{\mathrm{Ag}}^{+} / \mathrm{Ag}$ in the graphs presented in this manuscript.

A CHI 1000 A (Electro Analytical System) was employed for electropolymerisation of EDOT by sequential potential cycling, controlled potential deposition of $\mathrm{Cu}$ and for the estimation of Pd content by CV. Oxygen reduction reaction was examined by rotating disk electrode (RDE) and rotating ring disk electrode (RRDE) supplied by Pine instrument. Morphological details were estimated by various techniques as described us earlier ${ }^{24}$. The information related to the structure and size of the Pd/PEDOT/GC and Cu/PEDOT/GC catalysts were obtained by transmission electron microscopy (TEM) (FEI Tecnai $20 \mathrm{G} 2$ ). X-ray diffraction (XRD) studies were conducted by preparing the nanostructured catalyst on a ITO substrate, by following the same method with a Bruker D8 Advance X-ray diffractometer with Ni-filtered $\mathrm{Cu} \mathrm{K}$ radiation $(\lambda=1.5406 \AA)$ at the scan rate of $3 \%$ min in steps of $0.05^{\circ}$. The percentage of $\mathrm{Pd}$ and $\mathrm{Cu}$ on PEDOT was investigated by EDAX (Hitachi S- $3000 \mathrm{H}$ scanning electron microscope) and the distribution of $\mathrm{Cu}$ and Pd on PEDOT was examined by a Carl Zeiss field-emission scanning electron microscope (SEM) (Supra $55 \mathrm{VP}$ ). The chemical states of the elements were determined by a Multilab 2000 Thermo Scientific X-ray photoelectron spectrophotometer (XPS) using a twin anode X-ray source (Mg $\mathrm{K}_{\alpha}$ radiation, $1253.6 \mathrm{eV}$ ). The XPS spectra were curve fitted and de-convoluted with XPS peak 4.1 software. The topography image was recorded by scanning probe microscopy Agilent technology (5500 series) and the image was processed by pico image basic software.

\section{Results and Discussion}

Spectral characterizations. FT-IR spectroscopy for Pd/PEDOT. The prepared catalyst has been examined by FTIR during every stage of electrode modification. Figure 1 depicts the FT-IR of the composite material which reveals the bonding interaction and the vibration modes in every functional group before and after doping $\mathrm{Cu}$ and $\mathrm{Pd}$. Figure la shows the vibrational bands at 1556 and $1386 \mathrm{~cm}^{-1}$ corresponding to the formation of $\mathrm{C}=\mathrm{C}$ and $\mathrm{C}-\mathrm{C}$ of the quinodial structure of thiophene ring, respectively.

The vibrational bands at 1209 and $1089 \mathrm{~cm}^{-1}$ are ascribed to the $\mathrm{C}-\mathrm{O}-\mathrm{C}$ stretching vibrations in ethylenedioxy group. The C-S band stretching in thiophene ring appeared at the absorption bands at 813 and $678 \mathrm{~cm}^{-1}$. The vibrational bands at $939 \mathrm{~cm}^{-1}$ is due to the ethylene dioxy ring deformation mode. The Fig. $1 \mathrm{~b}$ corresponding to $\mathrm{Cu}$ NPs functionalized polymer matrix, reveals that the peak corresponding to dioxy group is missing which shows that the $\mathrm{Cu}$ is complexed at the oxygen site. A marginal change is observed in the C-S region, indicating only insignificant complexation of $\mathrm{Cu}$ atoms at the Sulphur site. In the case of the Pd NPs decorated PEDOT/GCE the intensity of the peaks increased due to the doping of Pd NPs as shown in Fig. 1c.

$X$-ray diffraction analysis. The XRD spectrum shown in Fig. 2a reveals a peak at a $2 \theta$ value of $24.19^{\circ}$ which confirms the electropolymerization of EDOT and corresponds to planar chain stacking. The experimental XRD 


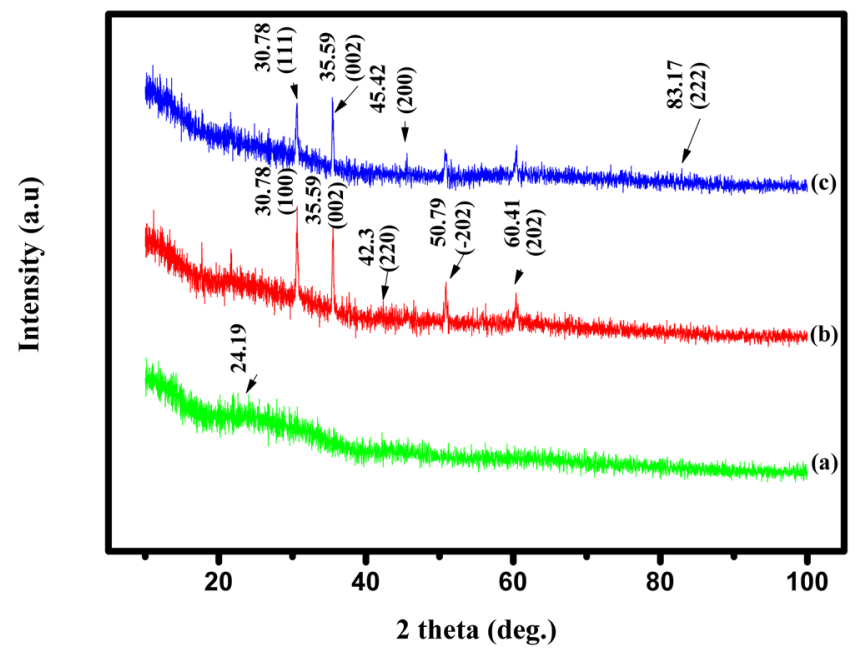

Figure 2. X-ray diffraction pattern for (a) electro polymerized EDOT monomer (PEDOT), (b) electrodeposited $\mathrm{Cu}$ on PEDOT under constant potential, and (c) galvanically replaced Pd on Cu-PEDOT.

peaks of $\mathrm{Cu}-\mathrm{PEDOT}$ are obtained at $30.78^{\circ}, 35.59^{\circ}, 42.3^{\circ}, 50.79^{\circ}$ and $60.41^{\circ}$. It denotes the electrochemical deposition of the copper nanoparticles (Fig. 2b) on PEDOT matrix. The observed peaks correspond to (100), (002), (220), (-202), and (202) crystal planes respectively, confirming the cubic structure of Cu (JCPDS 00-003-0892). The $\mathrm{Cu}$ is replaced by Pd NPs via galvanic replacement reaction in 30 minutes. The as prepared Pd/PEDOT/GC electrode (Fig. 2c) shows the peaks of palladium at $30.78^{\circ}, 35.59^{\circ}, 45.42^{\circ}$, and $83.17^{\circ}$ which signify (111), (002), (200), and (222) crystal planes (JCPDS 01-087-0637).

$X$-ray Photoelectron Spectroscopy. The chemical composition of Pd/PEDOT is determined by XPS analysis. The composite catalyst shows the presence of the elements $\mathrm{Pd}, \mathrm{Cu}, \mathrm{O}$, and $\mathrm{C}$. The Gaussian-Lorentzian fitting has been used for deconvolution of $\mathrm{Pd} 3 \mathrm{~d}, \mathrm{Cu} 2 \mathrm{p}, \mathrm{O} 2 \mathrm{~s}$, and $\mathrm{C} 1 \mathrm{~s}$, respectively. Figure $3 \mathrm{a}$ depicts the survey spectrum of the prepared catalyst where core level photo emissions for even trace level impurities are also detectable. The $\mathrm{O} 1 \mathrm{~s}$ appears at approximately $532.85 \mathrm{eV}$ but $\mathrm{Pd} 3 \mathrm{p}_{3 / 2}$ is also present in the same region. Hence $\mathrm{O} 2 \mathrm{~S}$ peaks are taken into consideration. The high resolution profile of $\mathrm{Pd} 3 \mathrm{~d}$ depicted in Fig. $3 \mathrm{~b}$ shows the pair of asymmetric peaks constituting the Pd $3 \mathrm{~d}$ signal. The binding energies (BEs) of $\mathrm{Pd} 3 \mathrm{~d}_{3 / 2}(342.43 \mathrm{eV})$ are $5.22 \mathrm{eV}$ lower than those of $\mathrm{Pd} 3 \mathrm{~d}_{5 / 2}(337.19 \mathrm{eV})$ for each doublet ${ }^{25}$. The intense doublet peaks belong to $\mathrm{Pd}(0)$ and the weak peaks are attributed to Pd (II) species, such as $\mathrm{Pd}(\mathrm{OH})_{2}$ and PdO.

The peak of $\mathrm{Cu}$ can be clearly seen at $930.74 \mathrm{eV}$ in the high-resolution spectrum of $\mathrm{Cu}$ in Fig. $3 \mathrm{c}$, which indicates distinct distributions of four $\mathrm{Cu}$ valence states; that is, the signals observed at $926.31 \mathrm{eV}, 930.74 \mathrm{eV}, 934.83 \mathrm{eV}$, and $941.98 \mathrm{eV}$ correspond to $\mathrm{Cu}^{+}, \mathrm{Cu}^{2+}, \mathrm{Cu}(\mathrm{OH})_{2}$ and $\mathrm{Cu}$ respectively. The feature at $930.74 \mathrm{eV}$ can be due to $\mathrm{Cu}^{+}$ or metallic $\mathrm{Cu}$. The $\mathrm{C} 1 \mathrm{~s}$ bond can be deconvoluted into three bands at $284.6 \mathrm{eV}, 285.9 \mathrm{eV}$ and $287.2 \mathrm{eV}$, which can be assigned to $\mathrm{C}=\mathrm{C}, \mathrm{C}-\mathrm{N}(\mathrm{C}=\mathrm{N})$ and $\mathrm{C}-\mathrm{O}(\mathrm{C}=\mathrm{O})$, respectively.

Morphological characterizations. Field Emission Scanning Electron Microscopy (FESEM). The morphologies of (a) GC, (b) PEDOT, (c) Cu-PEDOT, and (d) Pd/PEDOT were characterised by FESEM. The cleaned GC (Fig. 4a) surface indicates the absence of catalyst and the electropolymerized EDOT (PEDOT) on GC (Fig. 4b) surface reveals the 3D porous network structure of PEDOT. The electrochemically deposited Cu on PEDOT (Fig. 4c) resembles cube like structure and the formation of $\mathrm{Cu}$ cubes strongly depends on the time, concentration and number of cycles during electrochemical PEDOT deposition. The size of the $\mathrm{Cu}$ nano cubes varies from 63 to $152 \mathrm{~nm}$. The Pd/PEDOT/GC (Fig. $4 \mathrm{~d}$ ) prepared by galvanic replacement reaction of Cu by Pd, shows mosaic pattern resembling shrimp fish. Closely placed spherical Pd NPs knitted in the shape of shrimp fish is observed in the case of Pd/PEDOT/GC. It could be observed that Pd replaces the top layer of $\mathrm{Cu}$ atoms on $\mathrm{Cu}$ nanocubes on PEDOT matrix and takes the shape of nanorods.

The chemical composition of prepared bimetallic catalyst and their weight percentage has been estimated by FESEM-EDAX analysis and it reveals the presence of C, S, and $\mathrm{O}$ in the polymer backbone on GC (Fig. 4e-g) and the atomic percentage.

Transmission electron microscopy (TEM) analysis. Morphological textures of Cu-PEDOT and Pd/PEDOT were investigated by TEM analysis. The Cu-PEDOT depicted in Fig. 5a shows the three dimensional structure of $\mathrm{Cu}$ nanocubes on PEDOT matrix, and Pd nanoparticles are displayed in Fig. 5b. The formation of tiny sphere shaped $\mathrm{Pd}$ nanoparticles have the size of 2.8 to $8.5 \mathrm{~nm}$ range as depicted in Fig. 5b (inset image). The agglomerated Pd nanoparticles stretch over a length of $200 \mathrm{~nm}$ resembling a shrimp and it reveals the homogeneous distribution of Pd NPs on $\mathrm{Cu} / \mathrm{PEDOT}$ matrix.

The TEM-SAED pattern depicted in Fig. 5 c shows the cubic diffraction of $\mathrm{Cu}$ on PEDOT with (220), (020), (200), (-220), (-2-20), (-200), and (0-20) planes of Cu. The agglomerated polynomial Pd pattern (Fig. 6d) with 

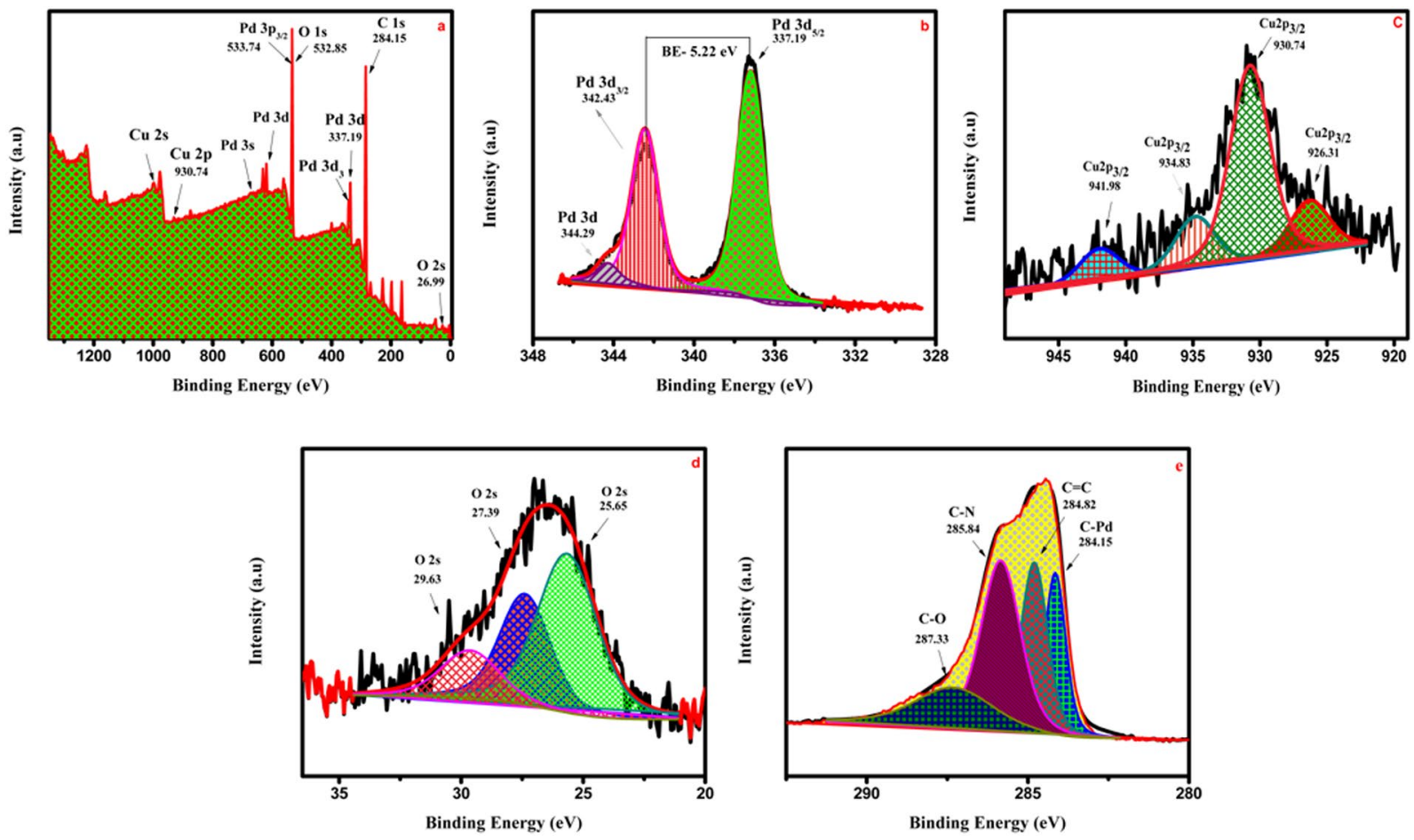

Figure 3. XPS analysis for electrochemically synthesised Pd/PEDOT catalyst, (a) survey spectrum showing characteristic photoemission of each element in the sample, (b) $\mathrm{Pd} 3 \mathrm{~d}_{5 / 2}$ and $\mathrm{Pd} 3 \mathrm{~d}_{3 / 2}$ spectral line, (c) Cu $2 \mathrm{p}_{3 / 2}$ spectral line, (d) O 2 s spectral line, and (e) C 1 s spectral line.

a homogenous distribution of Pd nanoparticles is clearly displayed as a ring arising from the diffraction pattern of (111), (200), and (220) planes of Pd respectively.

Atomic force microscopy (AFM) analysis. Surface morphology, thickness and roughness of the electrodes have been studied by AFM analysis. The topography of the modified electrode surface shown in Fig. 6a displays the electrochemical intercalation of PEDOT with high surface roughness that can act as a gateway for the allocation of $\mathrm{Cu}^{2+}$ ions (Fig. 6b). The electrodeposition of $\mathrm{Cu}$ on PEDOT has less roughness factor compared to PEDOT. The galvanically replaced Pd/PEDOT shown in Fig. 6c shows relatively a high surface roughness $(R a)$ and root mean square $(R q)$ compared to $\mathrm{Cu}-\mathrm{PEDOT}$. The increased surface roughness shows the adherence of $\mathrm{Pd}$ on $\mathrm{Cu}$ revealing the union of two surfaces.

Electrochemical studies. Electrochemical characterization of PEDOT on GC. A uniform growth of PEDOT on GC surface was formed by cyclic voltammetry during electropolymerization in 10 cycles between the potentials $-0.65 \mathrm{~V}$ and $+1.25 \mathrm{~V} v s$. an $\mathrm{Ag}^{+}$pseudo reference electrode. A Pt foil was used as the counter electrode. Figure 7 depicts the uniform deposition of PEDOT formation on clean GC surface. After polymerization, the GC electrode was washed with acetonitrile solution to remove the excess PEDOT or unreacted monomer of PEDOT. A smooth thin film of PEDOT could be formed by this method as reported earlier through other approaches ${ }^{26,27}$.

$$
m=\frac{\left(Q_{d e p 1}\right) M_{1}}{F Z_{1}}
$$

The mass of PEDOT $(m)$ was calculated from the total charge of the film after polymerization process, using the amount of charge $\left(Q_{\mathrm{dep} 1}\right)$, and assuming $100 \%$ current efficiency $(\eta)$ (the total charge passed through the cell during the polymer film growth process). $M_{1}$ is the molecular weight of EDOT, $F$ is the Faraday constant $(96,485$ $\left.\mathrm{Cmol}^{-1}\right) \cdot Z_{1}$ (=2 here) is the number of electrons transferred ${ }^{28}$. The columbic equivalent for the obtained PEDOT film was found to be $0.040109 C$ and the mass of PEDOT was calculated as $2.974 \times 10^{-5} \mathrm{~g}$.

Electrochemical characterization of $\mathrm{Cu}$-PEDOT. The $\mathrm{Cu}$ is potentiostatically deposited on PEDOT in $0.1 \mathrm{M}$ $\mathrm{NaClO}_{4}$ containing $2 \mathrm{mM}_{\text {of }} \mathrm{CuSO}_{4}$ at an applied potential $+0.34 \mathrm{~V} v s$. SHE for a period of $120 \mathrm{~s}$ by using chronoamperometric (CA) technique. An abrupt increase in current density value is noticed at the initial stage which attained a steady state around $2 s$, indicating the nucleation and followed by uniform growth of $\mathrm{Cu}$ on PEDOT.

The controlled potential deposition and formation of $\mathrm{Cu}$ on PEDOT has been analysed by cyclic voltammetry which has been shown in Fig. 8a,b respectively. The redox features of $\mathrm{Cu}$ appears at $0.36 \mathrm{~V}$ on the anodic side and at $0.15 \mathrm{~V}$ on the cathodic side. The peak separation between the cathodic and anodic peaks is found to be $0.21 \mathrm{~V}$. 


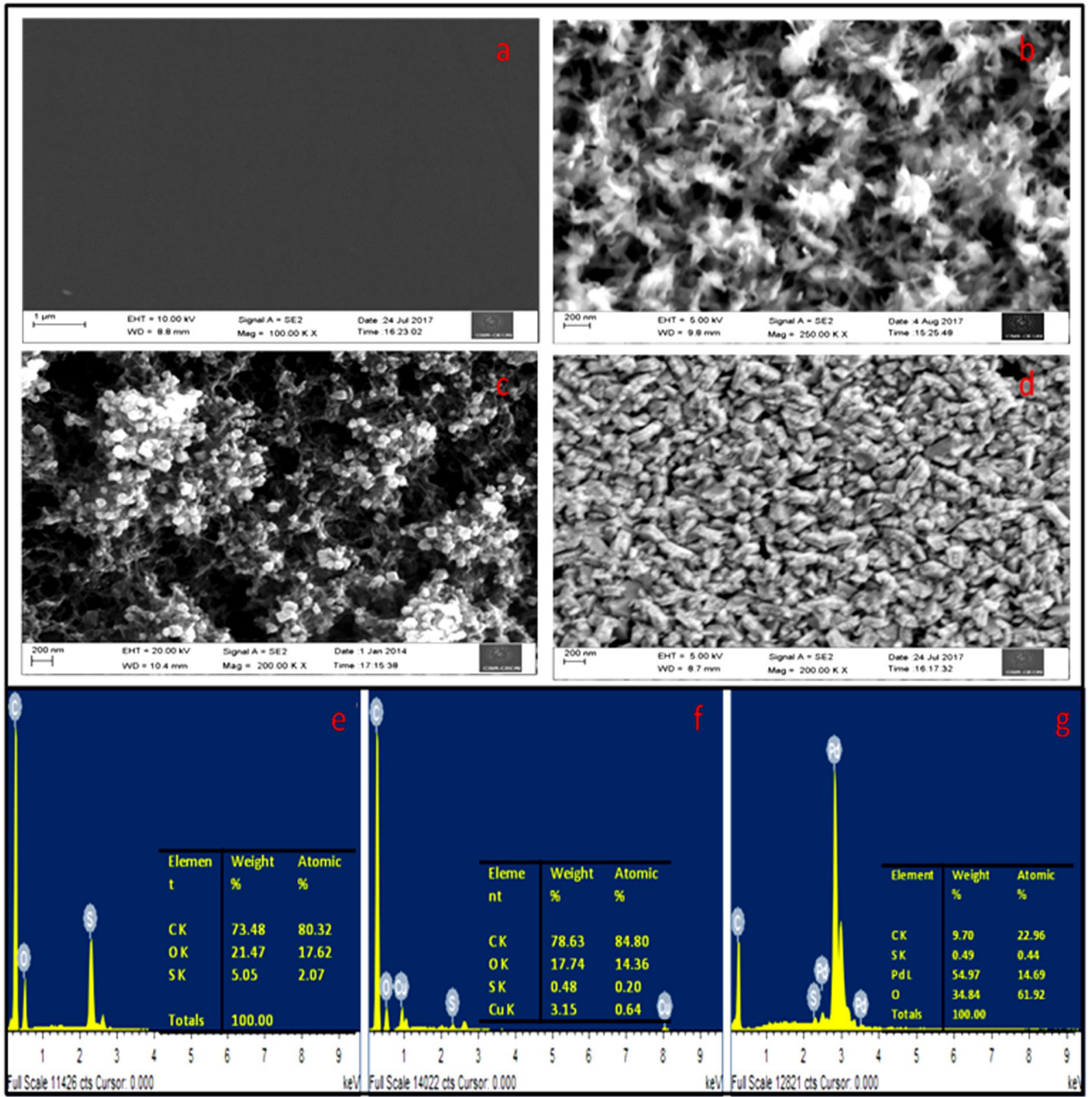

Figure 4. The morphological study of the electrode: FE-SEM images of (a) glassy carbon electrode, (b) $\operatorname{PEDOT}(\mathbf{c}) \mathrm{Cu} / \mathrm{PEDOT}$, and (d) Pd/PEDOT. FESEM-EDAX image of (e) PEDOT, (f) Cu/PEDOT and (g) Pd/ PEDOT.

The mass of $\mathrm{Cu}$ deposited on PEDOT was calculated from cyclic voltammetric data by integrating the charge corresponding to the reduction peak of $\mathrm{Cu}$, and was found to be $4.9354 \times 10^{-6} \mathrm{~g} / \mathrm{cm}^{2}$.

Electrochemical characterization of Pd/PEDOT. The Pd/PEDOT/GC was investigated by cyclic voltammetry in $0.5 \mathrm{M} \mathrm{H}_{2} \mathrm{SO}_{4}$ at a scan rate of $0.05 \mathrm{~V} / \mathrm{s}$ and the typical behaviour of Pd is evident in Fig. 9. The characteristic peak corresponding to Pd oxide formation and reduction is seen at $0.90 \mathrm{~V}$ and $0.67 \mathrm{~V}$. The HUPD region is not well resolved in Fig. 9a due to the presence of trace amount of $\mathrm{Cu}$ on the surface. Hence the Pd/PEDOT electrode was subjected to potential cycling between the $0 \mathrm{~V}$ to $0.14 \mathrm{~V} v \mathrm{~s}$. SHE five times in $0.5 \mathrm{M} \mathrm{H}_{2} \mathrm{SO}_{4}$. During cycling, the unreacted $\mathrm{Cu}$ will leach out from the surface as shown clearly in Fig. 9b. Pd ions are stable in an acid medium. Here, the $\mathrm{Cu}$ will act as a template or sacrificial anode for Pd/PEDOT/GC during cycling. The current peaks appearing between $0 \mathrm{~V}$ to $0.14 \mathrm{~V}$ vs. SHE are due to adsorption and desorption of hydrogen atoms on Pd/PEDOT catalyst in Fig. $9 \mathrm{~b}$.

The amount of Pd estimated from Pd/Cu-PEDOT/GC was found to be $0.56550 \times 10^{-9} \mathrm{~g} / \mathrm{cm}^{2}$ from the oxide reduction peak and the electrochemical active surface area (ECSA) was calculated based on the charge involved in the monolayer corresponding to oxygen adsorption/desorption on the Pd surface $\left(\mathrm{q}_{\mathrm{o}}\right)\left(424 \mu \mathrm{C} \mathrm{cm}{ }^{-2}\right)^{29}$ was $0.00145 \mathrm{~cm}^{2}$. The roughness factor $\left(\mathrm{R}_{\mathrm{f}}\right)$ of the electrocatalyst has been found to be 0.020546 . 

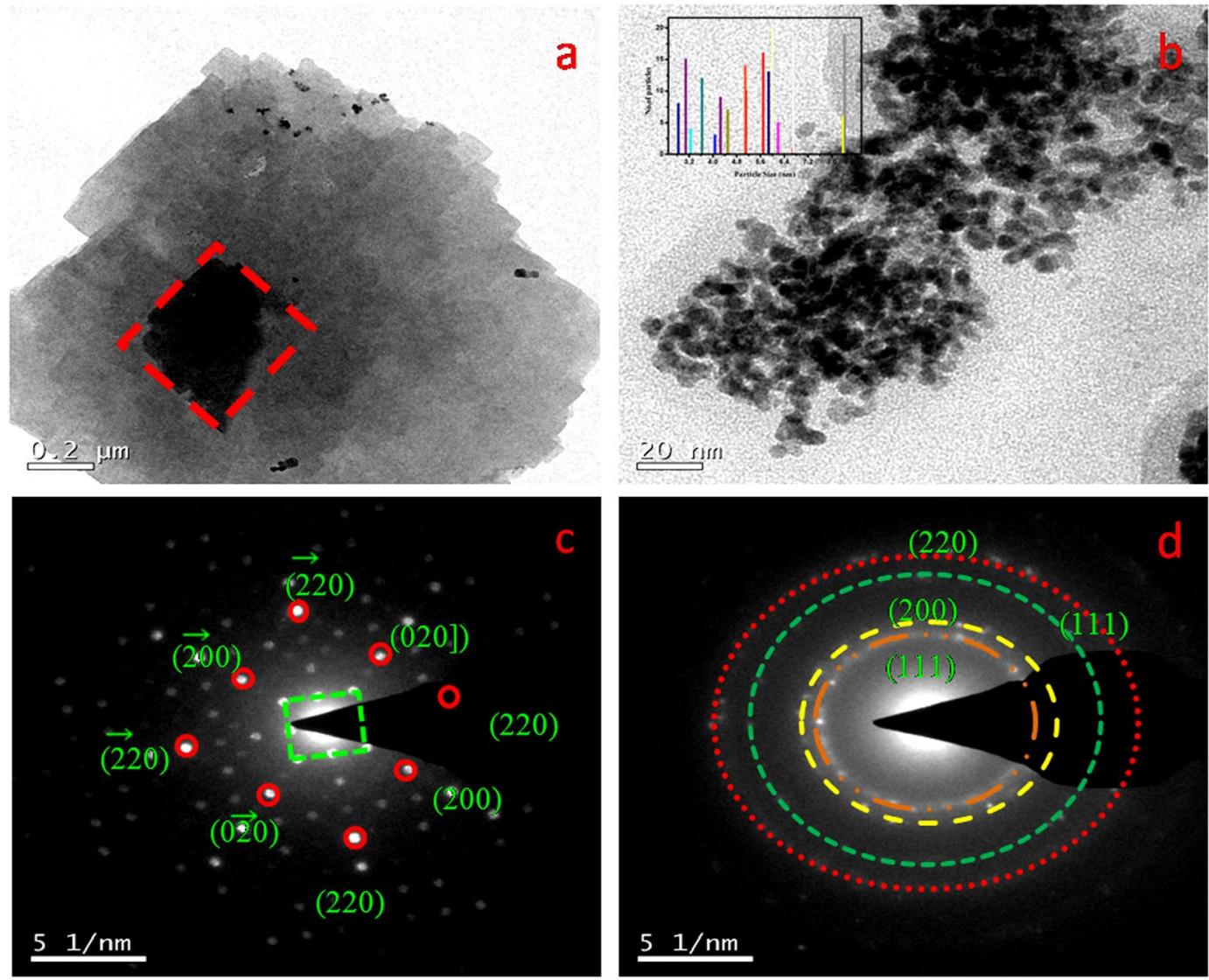

Figure 5. TEM analysis for (a) the Cu nanocubes formation on PEDOT surface (b) Pd nanoparticles agglomeration on $\mathrm{Cu}$ nanocubes on PEDOT, SAED pattern acquired from the irradiated substrate depicting the presence of (c) Cu nanocube on PEDOT, and (d) Pd NPs on Cu-PEDOT.
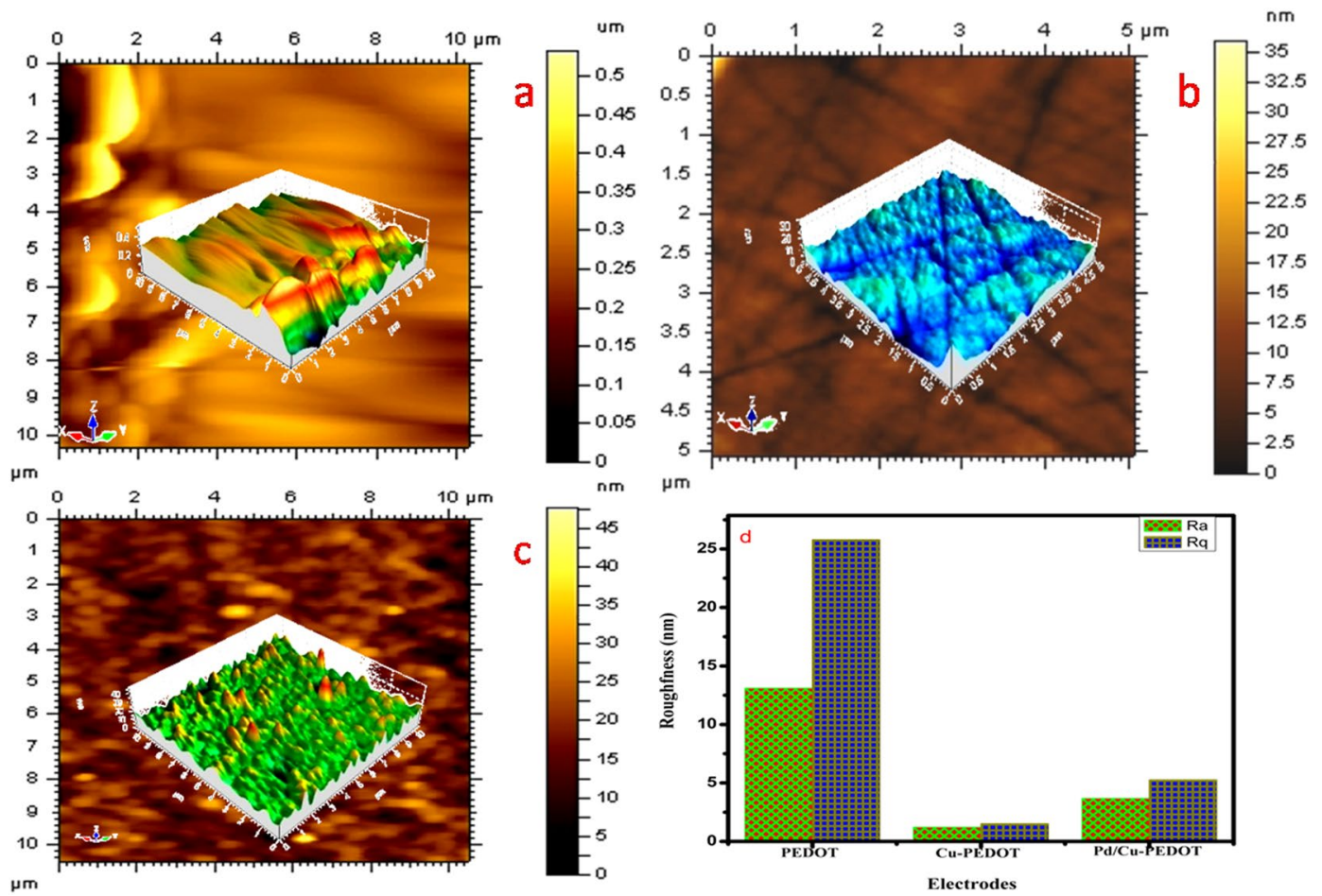

Figure 6. AFM images of glassy carbon modified electrodes at different stages of modification: (a) PEDOT, (b) $\mathrm{Cu} / \mathrm{PEDOT},(\mathbf{c}) \mathrm{Pd} / \mathrm{PEDOT}$, (d) root mean square and average roughness of the respective electrodes. 


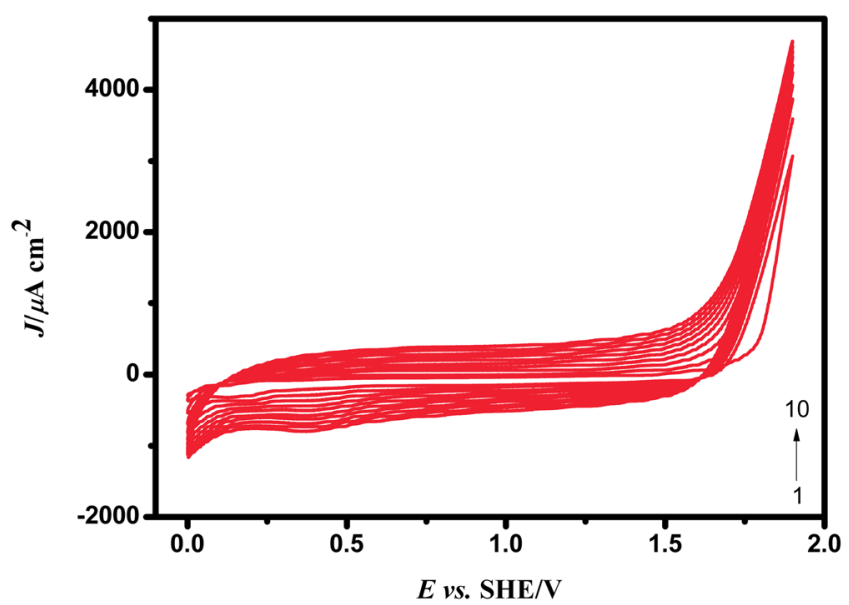

Figure 7. The electrochemical polymerization of EDOT on GCE by $20 \mathrm{mM}$ of EDOT with $50 \mathrm{mM}$ of tetrabutylammonium perchlorate in acetonitrile at a scan rate of $0.05 \mathrm{~V} / \mathrm{s} v \mathrm{~s}$. $\mathrm{Ag}^{+}$.
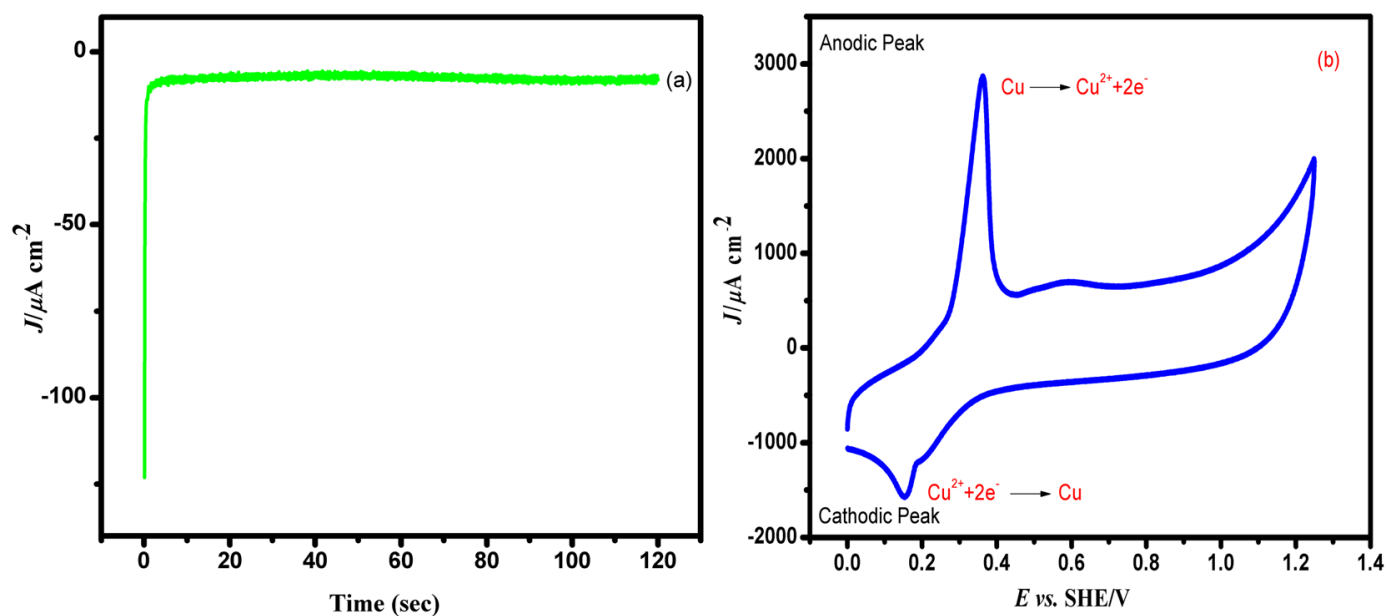

Figure 8. The $\mathrm{Cu}$ deposition on $\mathrm{PEDOT}$ matrix (a) in $2 \mathrm{mM} \mathrm{CuSO}_{4}$ with $0.1 \mathrm{M} \mathrm{NaClO}_{4}$ at a constant potential of $+0.34 \mathrm{~V}$ for $120 s$ and (b) CV responses for Cu-PEDOT/GC in $0.1 \mathrm{M} \mathrm{NaClO}_{4}$ at a scan rate of $0.05 \mathrm{~V} / \mathrm{s} v s$. SHE.
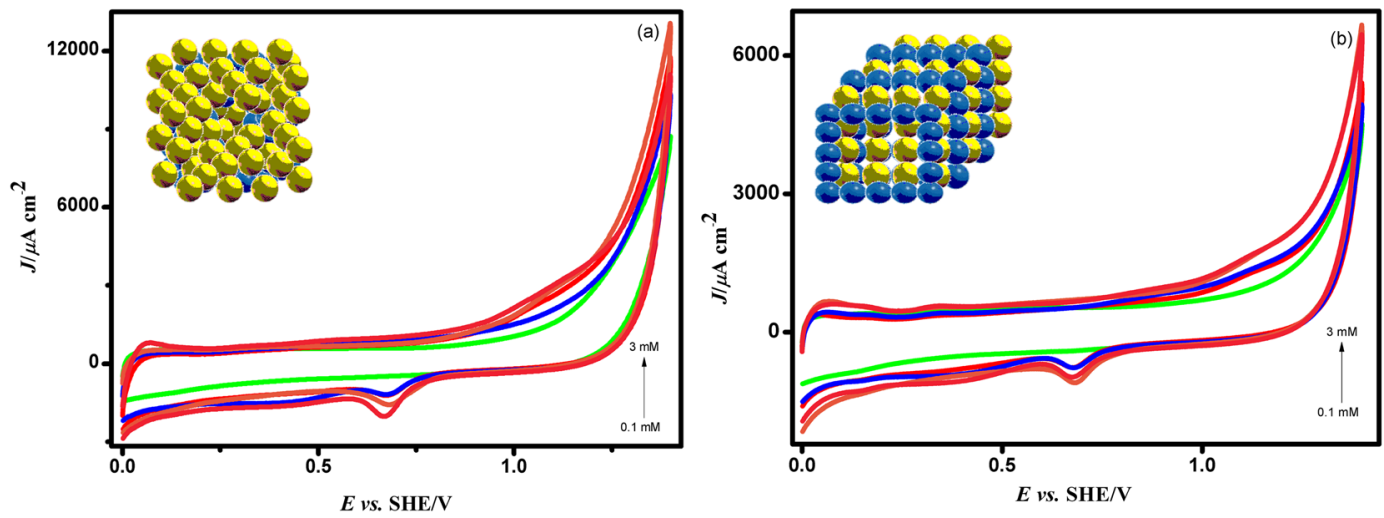

Figure 9. CV responses of $\mathrm{Pd} / \mathrm{PEDOT}$ (a) before and (b) after 5 potential cycles in $0.5 \mathrm{M} \mathrm{H}_{2} \mathrm{SO}_{4}$ with varying the concentrations of $0.1,0.5,1,2$, and $3 \mathrm{mM}$ of $\mathrm{PdCl}_{2}$ in the potential range between $0.0 \mathrm{~V}$ and $1.3 \mathrm{~V}$ at a scan rate of $0.05 \mathrm{~V} / \mathrm{s} v s$. SHE. 

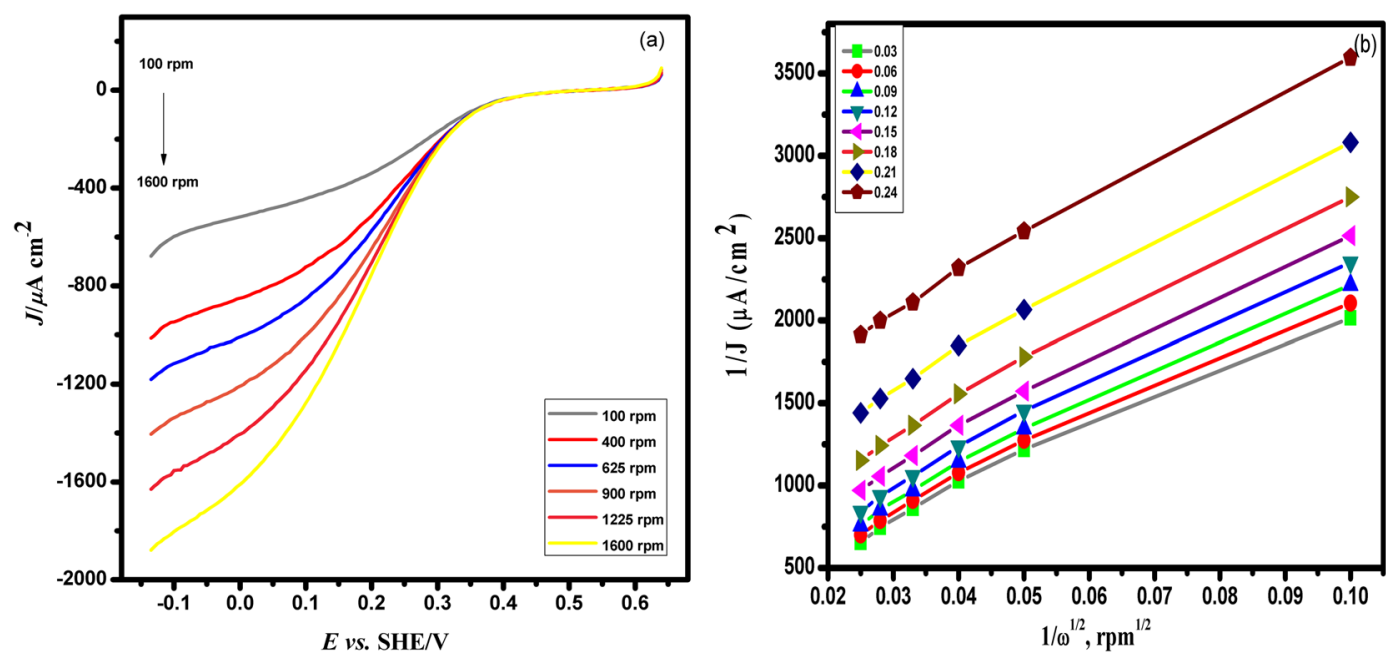

Figure 10. Polarization curve of ORR on (a) Pd/PEDOT electrocatalyst in $0.5 \mathrm{M} \mathrm{H}_{2} \mathrm{SO}_{4}$ solution, and (b) Koutecky - Levich plots at different potentials.

$$
P d_{E C S A}=\frac{\left(Q_{P t^{0}}\right)}{424 \mu C \cdot \mathrm{cm}^{-2}}
$$

where, $Q_{P t}{ }^{0}$ is the charge corresponding to oxide reduction region in coulombs $(\mathrm{C})$, the monolayer charge corresponding to oxygen adsorption/desorption on the Pd surface is $424 \mu \mathrm{C} \mathrm{cm}$.

ORR activity of $P d / P E D O T$ electrocatalyst. Oxygen reduction reaction is one of the important factors determining the efficiency of fuel cell cathode catalysts. The Pd/Cu-PEDOT/GC exhibits electrocatalytic properties towards oxygen reduction reaction. Figure 10 a depicts the polarization curves obtained for different rotation rates for $\mathrm{Pd} / \mathrm{PEDOT}$ catalyst in $\mathrm{O}_{2}$-saturated $0.5 \mathrm{M} \mathrm{H}_{2} \mathrm{SO}_{4}$ solution. Obviously, $\mathrm{Pd} / \mathrm{PEDOT}$ catalyst exhibits a half wave potential at $0.48 \mathrm{~V}$ for the $\mathrm{ORR}$, which is nearly $0.3 \mathrm{~V}$ more negative as compared with that of the commercial Pd/C catalyst $(0.78 \mathrm{~V})$. The Tafel plot of the kinetic currents $j_{\mathrm{k}}$ of Pd/PEDOT is shown in the Figure S1

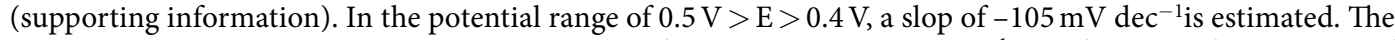
Koutecky-Levich plot (Fig. 10b) showing the plot of inverse current density $\left(j^{-1}\right)$ as a function of square root of the rotation inverse $\left(\omega^{-1 / 2}\right)$ and the parallelism and linearity of these plots indicates that the molecular oxygen reduction follows first order kinetics ${ }^{30}$.

$$
\frac{1}{j}=\frac{1}{j_{k}}+\frac{1}{B \omega^{1 / 2}}
$$

The slope of the K-L plots provides an $\mathrm{n}$ value of around 2 (see supporting information for the calculation of electron number). It varies from 2.155 to 2.864 in the range of potentials $0.03 \mathrm{~V}$ to $0.24 \mathrm{~V}$. Figure 11 depicts the RRDE measurements for the Pd/PEDOT electrode using the rotation rate which exhibits lower onset potential of oxygen at $0.51 \mathrm{~V}$ and half wave potential at $0.48 \mathrm{~V} v s$. SHE which are lower compared to other Pt loaded catalyst ${ }^{31}$.

The percentage of the current associated with the peroxide generation at $0.01 \mathrm{~V} v s$. SHE has been calculated by using following Eq. 4 .

$$
\% H_{2} \mathrm{O}_{2}=\frac{2 I_{R} / N}{I_{D}+\left(I_{R} / N\right)}
$$

where $I_{R}$ and $I_{D}$ are the disk and ring currents and $\mathrm{N}$ represent collection efficiency. The percentage of the current associated with the peroxide generation at $0.01 \mathrm{~V} v s$. SHE is $8.8 \%$. ORR shows onset around $0.51 \mathrm{~V}$ vs. SHE and gradually current increases approximately to $0.2 \mathrm{~mA} / \mathrm{cm}^{2}$ at $100 \mathrm{rpm}$. The recorded rpm effect depicts the significant increments in the current with respect to mass transfer process. The proposed mechanism for oxygen reduction is as follows:

$$
\begin{gathered}
\mathrm{O}_{2}+2 \mathrm{H}^{+}+2 e^{-} \rightarrow \mathrm{H}_{2} \mathrm{O}_{2} \\
2 \mathrm{H}_{2} \mathrm{O}_{2} \rightarrow 2 \mathrm{H}_{2} \mathrm{O}+\mathrm{O}_{2}
\end{gathered}
$$

The low $\%$ of $\mathrm{H}_{2} \mathrm{O}_{2}$ indicates that the product $\mathrm{H}_{2} \mathrm{O}_{2}$ obtained by 2 e transfer (Eq. 3 ) undergoes chemical decomposition to oxygen. Hydrogen evolution follows immediately after oxygen reduction at a potential as low as $-0.1 \mathrm{~V}$ vs. SHE. 


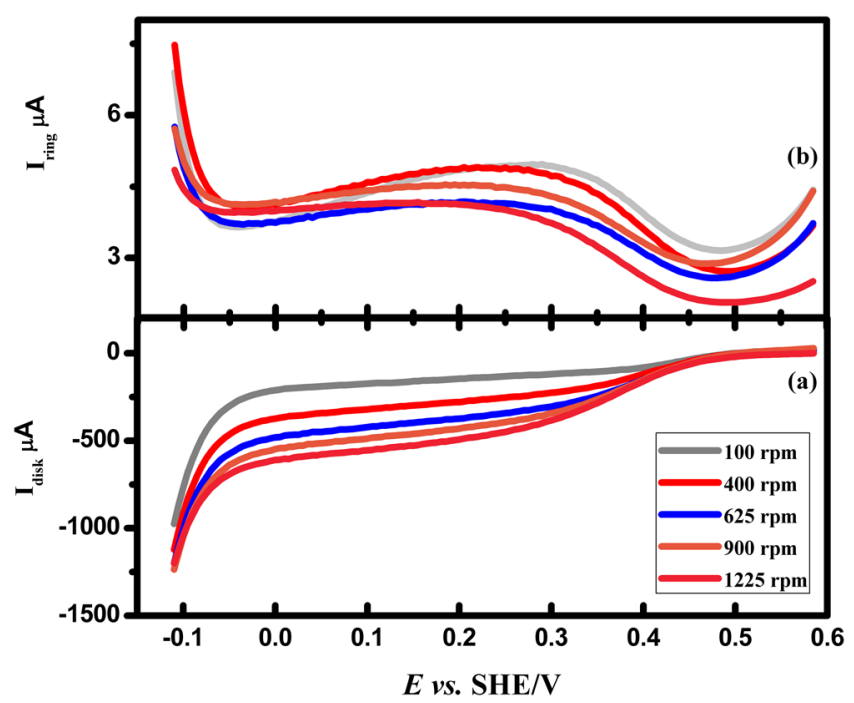

Figure 11. Rotating ring disk electrode (RRDE) measurement of the oxygen reduction reaction (ORR) for Pd/ PEDOT electrocatalyst in $0.5 \mathrm{M} \mathrm{H}_{2} \mathrm{SO}_{4}$ solution at a scan rate of $0.02 \mathrm{~V} / \mathrm{s}$.

\begin{tabular}{|c|c|c|c|c|c|c|c|}
\hline Sl.No & Name of the catalyst & $\begin{array}{l}\text { Onset potential } \\
\text { (V vs. SHE) }\end{array}$ & $\begin{array}{l}\text { Tafel slop value } \\
\text { (mV/dec) }\end{array}$ & Medium & $\begin{array}{l}\text { Current density; } \\
\text { RDE data }\left(\mathrm{mA} / \mathrm{cm}^{2}\right)\end{array}$ & $\begin{array}{l}\text { No. of } \\
\text { electrons (n) }\end{array}$ & Reference \\
\hline 1 & Pd/Activated Carbon & 0.58 & - & $0.5 \mathrm{M} \mathrm{HClO}_{4}$ & $1.1^{*}$ & - & 33 \\
\hline 2 & $\mathrm{Pd} / \mathrm{LaFeO}_{3}$ & 0.66 & 92 & $0.1 \mathrm{M} \mathrm{KOH}$ & 3.92 & 2.21 & 34 \\
\hline 3 & Pd/WC-700-m & 0.69 & - & $0.1 \mathrm{M} \mathrm{NaOH}$ & 2 & 3.0 & 35 \\
\hline \multirow{3}{*}{4} & Pt/C (commercial) & 1.04 & & & & & \\
\hline & PdNi dealloyed & 1.04 & - & $0.1 \mathrm{M} \mathrm{HClO}_{4}$ & - & - & 36 \\
\hline & Pd dealloyed & 0.90 & & & & & \\
\hline \multirow[t]{2}{*}{5} & $\begin{array}{l}\text { NM (Nanotubular } \\
\text { Mesoporous) -Pd }\end{array}$ & 0.90 & 67 & $0.1 \mathrm{M} \mathrm{HclO}_{4}$ & 6.0 & 4 & 37 \\
\hline & $\mathrm{Pd} / \mathrm{C}$ & 0.95 & 88 & & 5.0 & & \\
\hline 6 & Pd/PEDOT & 0.51 & 105 & $0.5 \mathrm{M} \mathrm{H}_{2} \mathrm{SO}_{4}$ & 1.8 & 2.8 & This work \\
\hline \multirow{2}{*}{7} & $\mathrm{Pd} / \mathrm{rGO}$ & 0.86 & 121 & & - & 2.1 & 3 \\
\hline & $\mathrm{Pd} / \mathrm{PEDOT} / \mathrm{rGO}$ & 0.98 & 152 & $0.1 \mathrm{M} \mathrm{KOH}$ & 0.82 & 3.7 & \\
\hline
\end{tabular}

Table 1. Performance comparison of Pd based catalysts on different supporting matrices. *Taken from CV data at $0.1 \mathrm{~V} / \mathrm{s}$.

The performance of Pd based catalysts prepared using different supporting matrices have been compared and the results are given in Table 1 . The onset potential obtained by us is on par with Pd catalysts prepared using activated carbon supports. It is observed from the table that the inclusion of second metal either as alloy or bimetallic form has shifted the onset potentials to more positive values equivalent to that of $\mathrm{Pt} / \mathrm{C}$ commercial catalysts. Hence we propose to introduce the second metal also into this Pd/PEDOT matrix by galvanic replacement in future studies.

Linear sweep voltammetry studies. Pd/PEDOT/GC electrode shows a significant enhancement of the cathodic peak indicating the high electrocatalytic activity of the Pd/PEDOT/GC electrocatalyst (Fig. 12a). The directly deposited Pd on PEDOT/GC (control experiment) could show only a lower electrocatalytic activity towards ORR in the absence of $\mathrm{Cu}$ template. The galvanically replaced $\mathrm{Pd} / \mathrm{PEDOT} / \mathrm{GC}$ has provided favourable electroactive sites, resulting in more favourable electron transfer kinetics and enhanced electrocatalytic performance towards oxygen reduction in the $\mathrm{Pd} / \mathrm{PEDOT} / \mathrm{GC}$ electrode. Interestingly the galvanically replaced $\mathrm{Pd} / \mathrm{PEDOT}$ catalyst exhibits the onset potential at $0.728 \mathrm{~V} v s$. SHE and the half wave potential occurs at $0.345 \mathrm{~V}$. The mass and specific activities of the Pd/PEDOT catalyst have been calculated as $1.78 \mathrm{~A} / \mathrm{g}$ and $1009.48 \mu \mathrm{A} / \mathrm{cm}^{2}$.

Methanol tolerant reaction for Pd/PEDOT/GC electrocatalyst. Currently Pt-containing cathode catalyst does not exhibit much tolerance towards methanol and it leads to decrease in the efficiency of the DMFCs ${ }^{32}$. To investigate such effects, the methanol crossover has been carried out in presence of Pd/PEDOT electrocatalyst in $0.5 \mathrm{M}$ $\mathrm{H}_{2} \mathrm{SO}_{4}$ solution containing $0.5 \mathrm{M}$ to $5 \mathrm{M}$ methanol as depicted in Fig. 13. There is no evidence for methanol oxidation and even at high concentrations of methanol the catalyst current has decreased by $1.212 \times 10^{-4} \mathrm{~A} / \mathrm{cm}^{2}$. This might reflect the blocking of adsorbed methanol or some intermediates ${ }^{30}$. In this aspect Pd/PEDOT 

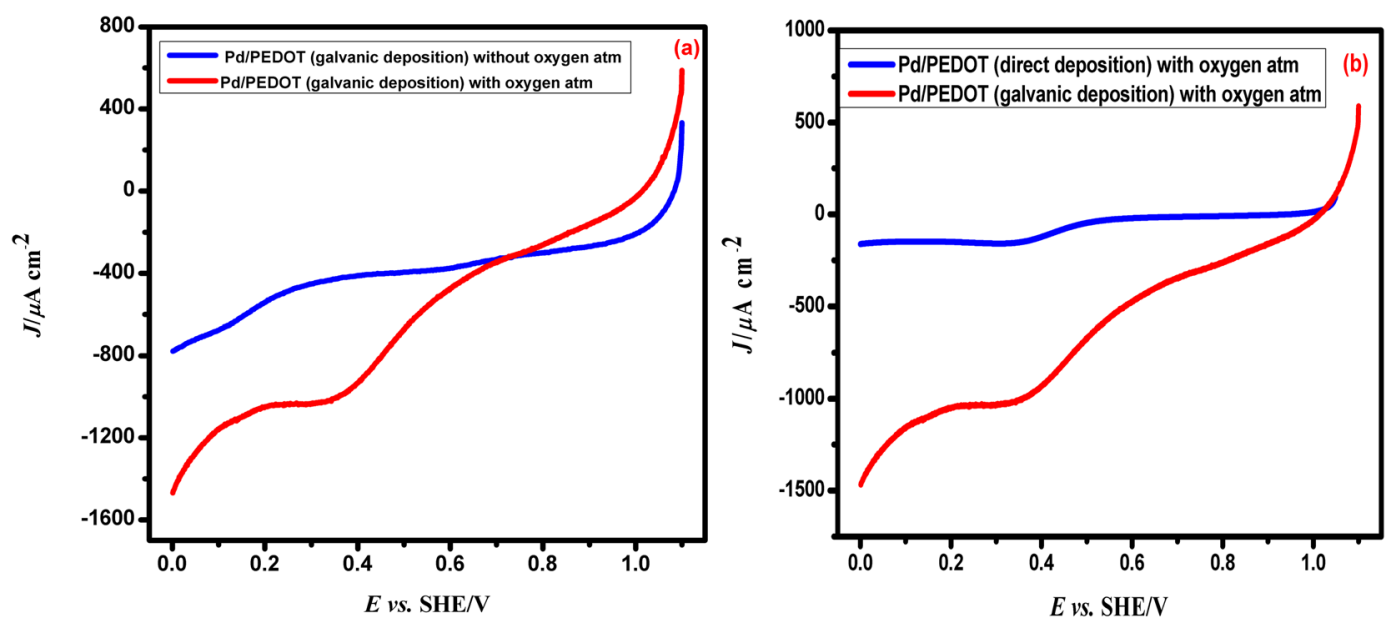

Figure 12. The linear sweep voltammetric response of (a) galvanically deposited Pd/PEDOT without oxygen, and with oxygen in a $0.5 \mathrm{M}$ of $\mathrm{H}_{2} \mathrm{SO}_{4}$ solution. Scan rate employed is $0.05 \mathrm{~V} / \mathrm{s}$. (b) the ORR response of directly deposited Pd/PEDOT and galvanic deposited Pd/PEDOT in $0.5 \mathrm{M}$ of $\mathrm{H}_{2} \mathrm{SO}_{4}$ solution with dissolved oxygen is shown in the figure.

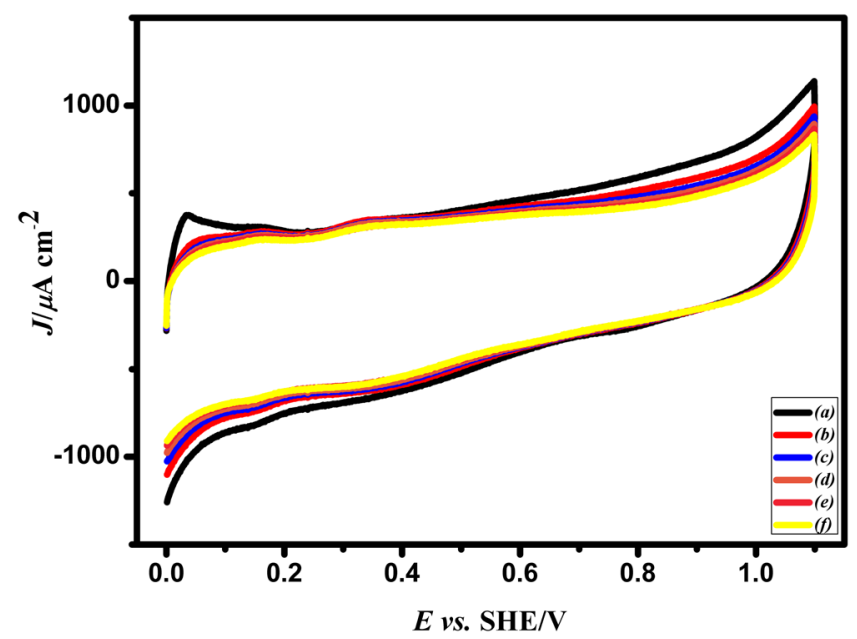

Figure 13. CV responses of (a) Pd/PEDOT for successive additions of methanol before, and (b-f) after each addition of $1 \mathrm{M} \mathrm{CH}_{3} \mathrm{OH}$ in $0.5 \mathrm{M} \mathrm{H}_{2} \mathrm{SO}_{4}$ in the potential range from $0.0 \mathrm{~V}$ to $1.3 \mathrm{~V}$ at a scan rate of $0.05 \mathrm{~V} / \mathrm{s} v s$. SHE.

electrocatalyst might be resolving the problem of methanol crossover in DMFCs. The Figure S2 shows effect of methanol tolerance in presence of oxygen and it indicates facile ORR kinetics in the presence of methanol.

\section{Conclusion}

$\mathrm{Pd} / \mathrm{PEDOT}$ catalyst was prepared on a glassy carbon surface by initially depositing Cu nanocubes on PEDOT surface under constant potential followed by the formation of Pd on $\mathrm{Cu}$ by GDR (galvanic displacement reaction). Superior methanol tolerance property has been observed for this Pd/PEDOT electrocatalyst. This catalyst, favours water formation via hydrogen peroxide production in $0.5 \mathrm{M} \mathrm{H}_{2} \mathrm{SO}_{4}$ with dissolved oxygen. It indicates the superior tolerance for methanol oxidation as well as supports oxygen reduction reaction with $2 \mathrm{e}^{-}$electron transfer yielding $\mathrm{H}_{2} \mathrm{O}_{2}$ which undergoes fast chemical decomposition to water. This paper brings out the catalytic activity of the galvanically replaced Pd nanostructures on PEDOT surface. The morphological analysis carried out during each stage of modification by FE-SEM and TEM analysis, showed a clear transition from porous morphology of PEDOT to nanocube formation of $\mathrm{Cu}$ on PEDOT followed by Pd deposit on $\mathrm{Cu}$ nanocubes by GDR in the form of uniform agglomeration of Pd nanoparticles with shrimp like structure. Thus prepared electrocatalyst can be used as methanol resistant fuel cell cathode. This concept can open a new avenue to create similar type of catalysts from other Pt group metals with definite structural morphology on polymer matrix for applications in sensing and catalysis using electrochemical approach.

Received: 24 October 2018; Accepted: 2 December 2019;

Published online: 16 December 2019 


\section{References}

1. Khurmi, R. S Material Science S Chand Publishing, New Delhi (1987).

2. Zhua, S. \& Shao, M. Impacts of ions on oxygen reduction reaction kinetics on platinum and palladium surfaces. ECS Transactions., 85, 15-24, 10.1149/08512.0015ecst. @The Electrochemical Society (2018).

3. Yoo, E. J. et al. Enhanced electrocatalytic activity of Pt subnanoclusters on graphene nanosheet surface. Nano Lett. 9, 2255-2259, https://doi.org/10.1021/n1900397t (2009).

4. Schmidt, T. J., Behm, R. J., Grgur, B. N., Markovic, N. M. \& Ross, P. N. Formic acid oxidation on pure and Bi-modified Pt (111) temperature effects. Langmuir. 16, 8159-8166, https://doi.org/10.1021/la000339z (2000).

5. Levia, E., Iwasita, T., Herrero, E. \& Feliu, J. M. Effect of adatoms in the electrocatalysis of $\mathrm{HCOOH}$ oxidation: a theoretical model. Langmuir. 13, 6287-6293, https://doi.org/10.1021/la970535e (1997).

6. Kang, S., Lee, J., Lee, J. K., Chung, S. Y. \& Tak, Y. Influence of Bi modification of Pt anode catalyst in direct formic acid fuel cells. J Phys Chem B. 110, 7270-7274, https://doi.org/10.1021/jp056753v (2006).

7. Lovic, J. D. et al. Kinetic study of formic acid oxidation on carbon-supported platinum electrocatalyst. J.Electroanal Chem. 581, 294, https://doi.org/10.1016/j.jelechem.2005.05.002 (2005).

8. Bell, A. T. The impact of nanoscience on heterogeneous catalysis. Science. 299, 1688-1691, https://doi.org/10.1126/science.1083671 (2003).

9. Wu, X. F., Anbarasan, P., Neumann, H. \& Beller, M. From Noble metal to nobel prize: palladium-catalyzed coupling reactions as key methods in organic synthesis. Angew Chem Int Ed. 49, 9047-9050, https://doi.org/10.1002/anie.201006374 (2010).

10. Erlebacher, J., Aziz, M. J., Karma, A., Dimitrov, N. \& Sieradzki, K. Evolution of nanoporosity in dealloying. Nature. 410, 450-453, https://doi.org/10.1038/35068529 (2001).

11. Stamenkovic, V. R. et al. Trends in electrocatalysis on extended and nanoscale Pt-bimetallic alloy surfaces. Nat Mater. 6, 241-247, https://doi.org/10.1038/nmat1840 (2007).

12. Xu, D. et al. Solution-based evolution and enhanced methanol oxidation activity of monodisperse platinum-copper nanocubes. Angew Chem Int Ed. 48, 4217-4221, https://doi.org/10.1002/anie.200900293 (2009).

13. Wu, J. et al. Truncated octahedral $\mathrm{Pt}_{3} \mathrm{Ni}$ oxygen reduction reaction electrocatalysts. J Am Chem Soc. 132, 4984-4985, https://doi. org/10.1021/ja100571h (2010).

14. Guo, Y. et al. $\mathrm{Pt}_{1}-\mathrm{Pd}_{3} \mathrm{Co}_{1}$ nanoparticles supported on multi-walled carbon nanotubes as a high performance electrocatalyst for methanol oxidation. Electrochem. Commun. 13, 886-889, https://doi.org/10.1016/j.elecom.2011.05.030 (2011).

15. Nørskov, J. K. et al. Origin of the overpotential for oxygen reduction at a fuel-cell cathode. J Phys Chem B. 108, 17886-17892, https:// doi.org/10.1021/jp047349j (2004).

16. Malinauskas, A. Electrocatalysis at conducting polymers. Synth Met. 107, 75-83, https://doi.org/10.1016/S0379-6779(99)00170-8 (1999).

17. Zarras, P. et al. Progress in using conductive polymers as corrosion-inhibiting coatings. Radiat Phys Chem. 68, 387-394, https://doi. org/10.1016/S0969-806X(03)00189-0 (2003).

18. Teles, F. R. R. \& Fonseca, L. P. Applications of polymers for biomolecule immobilization in electrochemical biosensors. Mater Sci Eng C. 28, 1530-1543, https://doi.org/10.1016/j.msec.2008.04.010 (2008).

19. Lange, U., Roznyatovskaya, N. V. \& Mirsky, V. M. Conducting polymers in chemical sensors and arrays. Anal Chim Acta. 614, 1-26, https://doi.org/10.1016/j.aca.2008.02.068 (2008).

20. Choe, J. E., Ahmed, M. S. \& Jeon, S. 3, 4-Ethylenedioxythiophene functionalized graphene with palladium nanoparticles for enhanced electrocatalytic oxygen reduction reaction. J Power Sources. 281, 211-218, https://doi.org/10.1016/j.jpowsour.2015.01.176 (2015).

21. Gómez, J. C. C., Moliner, R. \& Lázaro, M. J. Palladium-based catalysts as electrodes for direct methanol fuel cells: A Last Ten Years Review. Catalysts. 6, 130, https://doi.org/10.3390/catal6090130 (2016).

22. Wang, S. et al. Pd-based bimetallic catalysts prepared by replacement reactions. Catal Lett. 114, 169-173, https://doi.org/10.1007/ s10562-007-9064-2 (2007).

23. Lu, Xiaofeng et al. Noble-metal nanotubes prepared via a galvanic replacement reaction between $\mathrm{Cu}$ nanowires and aqueous $\mathrm{HAuCl}_{4}, \mathrm{H}_{2} \mathrm{PtCl}_{6}$, or $\mathrm{Na}_{2} \mathrm{PdCl}_{4}$. Sci Adv Mater. 2, 413-420, https://doi.org/10.1166/sam.2010.1105 (2010).

24. Pandia Rajathi, M., Sivakumar, C. \& Berchmans, S. Methanol electro-oxidation by nanostructured Pt/Cu bimetallic on poly 3, 4 ethylenedioxythiophene (PEDOT). Electrochimica Acta. 282, 163-170, https://doi.org/10.1016/j.electacta.2018.06.027 (2018).

25. Peng, W., Yiyin, H., Longtian, K., Maoxiang, W. \& Yaobing, W. Multisource synergistic electrocatalytic oxidation effect of strongly coupled $\mathrm{pdm}(\mathrm{m}=\mathrm{sn}, \mathrm{pb}) / \mathrm{n}$-doped graphene nanocomposite on small organic molecules. Scientific Reports. 5, 14173, https://doi. org/10.1038/srep14173 (2015).

26. Baglio, V. et al. Investigation of bimetallic Pt-M/C as DMFC cathode catalysts. Electrochimica Acta. 53, 1360-1364, https://doi. org/10.1016/j.electacta.2007.04.099 (2007).

27. Sandoval Gonzalez, A. et al. Methanol oxidation reaction on $\mathrm{PtSnO} 2$ obtained by microwave-assisted chemical reduction. Int $J$ Hydrog Energy. 37, 1752-1759, https://doi.org/10.1016/j.ijhydene.2011.10.049 (2012).

28. Zilan, F. et al. Electrosynthesis and electrochemical capacitive behavior of a new nitrogen PEDOT analogue based polymer electrode. New J Chem. 40, 2304-2314, https://doi.org/10.1039/C5NJ02054A (2016).

29. Nandan, R. \& Nanda, K. K. Rational geometrical engineering of palladium sulphide multi-arm nanostructures as a superior bifunctional electrocatalyst. Nanoscale. 9, 12628-12636, https://doi.org/10.1039/c7nr04733a (2017).

30. Anastasijevic, N. A., Vesovic, V. \& Adiic, R. R. Determination of the kin-etic parame ters of the oxygen reduction reaction using the rotating ring-disk electrode. J. Electroanal. Chem. 229, 305-316, https://doi.org/10.1016/0022-0728(87)85148-3 (1987).

31. Shao, M. H. et al. Palladium monolayer and palladium alloy electrocatalysts for oxygen reduction. Langmuir. 22, 10409-10415, https://doi.org/10.1021/la0610553 (2006).

32. Markovic, N. M. \& Ross, P. N. Electrocatalysts by design: from the tailored surface to a commercial catalyst. Electrochimica Acta. 45, 4101-4115, https://doi.org/10.1016/S0013-4686(00)00526-0 (2010).

33. Zheng, J. S. et al. Effect of carbon nanofiber microstructure on oxygen reduction activity of supported palladium electrocatalyst. Electrochem. Commun. 9, 895-900, https://doi.org/10.1016/j.elecom.2006.12.006 (2007).

34. Zhu, Y. et al. Boosting oxygen reduction reaction activity of palladium by stabilizing Its unusual oxidation states in perovskite. Chem. Mater. 27, 3048-3054, https://doi.org/10.1021/acs.chemmater.5b0045 (2015).

35. Ko, A. R. et al. Ordered mesoporous tungsten carbide nanoplates as non-Pt catalysts for oxygen reduction reaction. Appl. Catal. A 477, 102-108, https://doi.org/10.1016/j.apcata.2014.02.034 (2014).

36. Xu, C., Liu, Y., Hao, Q. \& Duan, H. Nanoporous PdNi alloys as highly active and methanol tolerant electrocatalysts towards oxygen reduction reaction. J. Mater. Chem. A. 1, 13542-13548, https://doi.org/10.1039/c3ta12765f (2013).

37. Xu, C. et al. Nanotubular mesoporous PdCu bimetallic electrocatalysts toward oxygen reduction reaction. Chem. Mater. 21, 3110-3116, https://doi.org/10.1021/cm900244g (2009).

\section{Acknowledgements}

The authors express their sincere thanks to Department of science and technology (DST) for financial support. They thank Dr. C. Sivakumar, senior scientist for his constant support and encouragement and keen interest in this work. They would also thank to CIF, KRC and CNF of CSIR-CECRI for providing specialities. 


\section{Author contributions}

The author P.R.M. carried out the experiments and prepared the initial draft. The author S.B. is responsible for the discussions and the preparation of the final manuscript.

\section{Competing interests}

The authors declare no competing interests.

\section{Additional information}

Supplementary information is available for this paper at https://doi.org/10.1038/s41598-019-55688-5.

Correspondence and requests for materials should be addressed to S.B.

Reprints and permissions information is available at www.nature.com/reprints.

Publisher's note Springer Nature remains neutral with regard to jurisdictional claims in published maps and institutional affiliations.

(c) (i) Open Access This article is licensed under a Creative Commons Attribution 4.0 International License, which permits use, sharing, adaptation, distribution and reproduction in any medium or format, as long as you give appropriate credit to the original author(s) and the source, provide a link to the Creative Commons license, and indicate if changes were made. The images or other third party material in this article are included in the article's Creative Commons license, unless indicated otherwise in a credit line to the material. If material is not included in the article's Creative Commons license and your intended use is not permitted by statutory regulation or exceeds the permitted use, you will need to obtain permission directly from the copyright holder. To view a copy of this license, visit http://creativecommons.org/licenses/by/4.0/.

(c) The Author(s) 2019 